\title{
Analyzing the Role of Motivation through the Job Design as a Moderate Factor on the Relationship between Personality Traits and Organizational Commitment
}

\author{
Zhiyar Mohammed Ismael \\ Department of Business Administration, Nawroz University, Kurdistan Region-Iraq
}

\begin{abstract}
This paper examines the moderate role of motivation on the relationship between the big five model of personality traits and organizational commitment as an attempt to understand the influence of multitude psychological and motivational factors on employees' behavior towards their organizational commitment.

In general, the idea of this framework is taken from personality aspect and Theory of Commitment of (Allen \& Meyer, 1996) which focus on how well the job is being performed by employees rather than only asking if they are doing their job. The basic foundation for forming and developing this new framework is: (1991) Allen \& Meyer's model of Organizational Commitment, Job Characteristics model of employee motivation for Hackman \& Oldham (1975), and Big Five Model of Personality for Cost \& McCrae.

In this study, data has been collected from surveying 241 employees of one of the private universities in Turkish Republic of Northern Cyprus (TRNC), results indicate that personality has a significant negative relationship with organizational commitment.

KEYWORDS: Big five model, Organizational Commitment, Affective Commitment, Continuance Commitment, Normative Commitment, Motivation.
\end{abstract}

\section{Introduction}

Organizational Commitment -rather than effective management principles- is considered the spine of organization's improvement and productivity. It is also a differentiating predictor between high performing organizations and those with average performance. Organizational Commitment is considered a wide researched aspect in organizational behavior studies. These studies helped organizations to best understand the relationship between organizational commitment and many different factors and then realizing their effects on organizational outcomes which consequently could help tailoring best solutions for organization's different obstacles and best contribute in sustaining organizational commitment (Ghosh \& Swamy, 2014; Woods \& West, 2010).

Through several past decades, many researches and efforts have reported a strong correction between Job Satisfaction and Organizational Commitment. Almost all these studies confirmed the importance of satisfaction for commitment because they discovered that individuals were not committed to their organizations when they felt dissatisfied (Ampofo, 2020), but we can say that sometimes even if the individuals are satisfied, they merely show up at their work and are not interested in achieving organization's vision. The main reason behind employees being not committed might go back to the availability of different psychological norms that form the personality of each person and create individual differences among people (Fowler et al, 2019). This aspect conceptualizes the framework of our study and tries to examine the effects of personality traits on organizational commitment, as well as, to identify which personality attitude leads employees to remain attached strongly with their organization and perform effectively, and which trait leads to a little contribution and weak attachment. 
Although few attempts are proposed to integrate motivation with commitment, but motivation seems to be an important antecedent for organizational commitment. Individuals might be motivated internally to do their work (intrinsic motivation) in accordance to availability of passionate believes such as willingness to complete and achieve success, relatedness to specific institution, or having autonomy and life control (Kaplan \& Tausky, 1972 ; Choong, Wong, \& Lau, 2011) , as well as, they may be motivated externally (extrinsic motivation) according to availability of over justification effects which could attribute personnel behaviors more toward conspicuous extrinsic motivation than to internal intrinsic believes (Altindls, 2011; Kuvaas et al, 2017).

The importance of this framework is epitomized in deeply understanding the work and personnel psychology aspects according to the interrelated effects of personality and extrinsic motivation on employees' behavior that will help organizations to seek and tailor best solutions to their problems and to achieve organizational development, effectiveness, and employees' well-being.

This research concentrates on conducting the moderate effects of extrinsic motivation factors on the relationship between personality traits and organizational commitment in order to discover if extrinsic motivation factors could change personnel norms toward organizational commitment or not.

In general, this study is going to investigate the following questions:

- How do the different personality traits affect the organizational commitment?

- How does motivation (through the job design) affect the relationship between personality traits and organizational commitment?

\section{Literature Review}

\subsection{Organizational Commitment}

Organizational Commitment has defined by Mowday, Steers, and Porter in 1979 as "the relative strength of an individual's identification with and involvement in a particular organization" (Brown, 1997). Accordingly, we can understand organizational commitment as individuals' emotional and psychological attachment to their organization.

\subsubsection{Taxonomies of Organizational Commitment} Dimensions

Many taxonomies of Organizational Commitment are proposed in organization theory through studying the situations and factors affecting individuals' attachment to their organizations, but the most common conceptualization which integrates all other taxonomies is the Three-Component Model of Commitment.

Allen and Meyer's (1991) commitment model, which is called Three- Component Model (TCM) demonstrates three different statuses of commitment practiced in various organizations according to the different psychological attachment of their personnel to the organization. TCM's components are:

affective commitment: a person is attached with his/her organization emotionally because they desire to stay and work towards achieving organizations goals.

- Continuance Commitment: employees need to keep working in their organizations in order not to lose economic, social costs among others.

- Narrative Commitment: employees feel responsible and loyal to their organizations.

In general, we can say that TCM describes the reasons behind the attachment of the employees and their commitment to their organizations as they would like to do so, need to do so, or ought to do so.

\subsection{Personality Traits in Organizations}

The study of individual differences is a comparatively mature field which approximately goes back to the beginning of the modern psychology. Individual differences are powerful factors that could enhance or frustrate the performance of organizations in 
nowadays volatile business environment.

Beer and Brooks (2011) defined personality as individuals' behaviors that distinguish or differentiate each person from another. Personality consider one of the most important antecedents of non- cognitive abilities that forms differences among individuals in the workplace and affects positively or negatively on carrying out the job; therefore, it is essential to assess and understand the characteristics of organization's different individuals and the new applicant that may influence different aspects related to the organizational behavior and person- job and personorganization fit (Shah \& Ayub, 2021).

\subsubsection{Big Five Model of Personality}

Many words are describing the different behaviors and personality traits of individuals but researchers could integrate, analyze, and summarize many personality characteristics that are indicating to the same dimension or trait of personality in which they grouped to specific categories that best represent each personality trait. Big five model of personality is considered one of the most famous and usable approaches of personality in which it categorizes personality to five basic aspects (Costa \& McCrae, 1992):

- Openness: Individuals whom set under this category of personality are tending to enjoy every new experience such as job, training, team, and mission. They are also eager to learn new information, skills, and ideas about different things, flexible to change, creative, open minded, able to find different solutions for one end, and prone to build new relationships (Kim, Bonn, Lee, C.-K., \& Kim, 2019).

- Conscientiousness: individuals whom associated with this category are responsible towards their authorized missions, systematic, organized and discipline, goal- achievement oriented, serious, careful, and dependable. Thus, conscientiousness is considered the most important trait of personality that predicts high performance and achievement, as well as representing individual's ability of self- control (Judge, Higgins, Thoresen, \& Barrick, 1999).

- Extraversion: individuals under this category tend to be talkative, always rounded by many people (sociable), spread joy in the place (energetic), willingness to attend social events. Thus, they mostly are successful in interviews because of their social skills (Caldwell \& Burger, 1998). Extravert individuals are not good in all jobs and show weak person- job fit specially in jobs that do not require a lot of non- cognitive abilities or social interaction. As well as, they probably record high levels of absenteeism (Min \& Su, 2020).

- Agreeableness: individuals under this category are nice, sensitive, helpful, and trusting. These characteristics have two side effects, a positive effect appears obviously when they represent in a leadership position because they treat individuals in a fair way, while the negative effects of agreeableness appear in some jobs that need high level of severity (Bauer \& Erdogan, 2012).

- Neuroticism: individuals under this category are experiencing nervousness and anxiety. They are also moody and experiencing depression and stress continuously, unhappy, panic, always complaining about their job environment and showing intention to leave the job without doing it. Thus, they are considered a source of disturbance and stress in the organization (Kim, Bonn, Lee, C.-K., \& Kim, 2019)

\section{Motivation}

The approach claiming that extrinsic motivation can easily affect and displace the value of the internal (intrinsic) motivation is strongly supported by many studies interested in analyzing motivation factors (Siachou et al, 2021; Mawhinney et al, 1989; Davidson 
\& Bucher, 1978).

Motivation can be defined as a set of forces or facts encouraging individuals to behave or act toward successful performance (goal- oriented behavior) (Baxter \& Pelletier, 2020).

\subsection{Motivating Employees According to Job Design}

The roots of job design go back to the ideas presented by a leader of scientific management Frederick Taylor in his book "principles of scientific management" 1911, the presented ideas had a great influence on organizing the work in the later years (De Jong et al, 2013; Taylor, 1911).

Organizations around the world differ according to differences in their jobs, and every job within the same organization is different in its design from others. Job or work design has a critical importance for employees, many evidences demonstrated that -over the time- individuals' personality, values, and attitudes are changing towards their organizations according to the design of their jobs (Rubenstein et al, (2019). Schooler and Kohn (1983) declared that high complexity jobs can enhance employees' abilities and intellectual functioning.

Many approaches are presented in motivating employees through the job design in which all of them agree upon one point which is encouraging and enhancing the desire of employees to work harder and become interested in achieving organization's goals through providing the proper and comfortable work environment that led them to feel satisfied and committed to their organization.

In this study, we concentrate on Job Characteristics Model in determining motivation's dimensions and items. This model is proposed by Hackman and Oldham. It described five core dimensions for job and is considered an important attempt for motivating employees through the job design (Hackman \& Oldham, 1975).
The five core job design dimensions are:

- Skill Variety: refers to the degree to which a specific job requires different skills, cognitive and non- cognitive abilities that enable the individual to carry out his/ her job's activities.

- Task Identity: refers to the extent to which a specific job requires accomplishing every detail of the work from the beginning till ending the final visible outcome.

- Task Significance: refers to the degree of job's importance and impact on other people lives, work, health, wellbeing, confidence, self- efficacy in the immediate firm or in the external environment which leads the worker to feel that his/ her job and efforts have a significant role and impact on the surrounding environment.

- Autonomy: refers to the degree that a job permits the employee to determine his/ her work schedule and procedures freely and independently to carry out the job. Autonomy can be classified in to three sections:

○ Work- scheduling autonomy

○ Decision- making autonomy

○ Work methods autonomy

- Feedback: refers to the degree in which individuals are informed about how effective they are at work. Individuals may receive feedback from other people such as supervisors, customers, co- workers, etc., or they may receive it directly during or after completing their work for the job results (Hackman \& Oldham, 1975).

\subsection{Hypotheses Generation}

Individuals' personalities are usually derived from theirs believes, feelings, and opinions towards their work environment. These attitudes are usually affecting on two basic aspects: job satisfaction and organizational commitment. Personality seems to have a most important impact on individuals' level of attachment to their organizations, but even if the person is not satisfied and tend to leave his/her job, 
this decision is not easy to be taken because it depends on many other aspects such as availability of other alternative jobs and if the new job requires the same skills or not and many other constraints. Thus, we can say that the personality of individuals is the determinant of all above attitudes, as well as it identifies to which dimension of commitment the person is related more.

- H1: personality traits relate at different percentages with organizational commitment.

Motivation as a moderate factor for the relationship between personality traits and organizational commitment:

Many studies interested in analyzing motivation factors have strongly supported the approach claiming that extrinsic motivation can easily affect and displace the value of the internal (intrinsic) motivation (Davidsom \& Bucher, 1978); (Mawhinne et al, 1989).

In accordance to the above idea, we can say that extrinsic motivation factors may affect individuals' altitudes, mindsets, and ethics. As work environment consider a critical aspect in customer satisfaction and organizational commitment, we tried to analyze the moderate role of motivation through job design and conduct their effects on the five factors of personality and the different dimensions of organizational commitment in order to better understand discretionary behavior in work place. So according to what we were looking forward to conduct, we hypothesized that:

- H2a: Job design has a significant moderate role on the relationship between extraversion and continues commitment.

- H2b: Job design has a significant moderate role on the relationship between conscientiousness and normative commitment.

- H2c: Job design has a significant moderate role on the relationship between agreeableness and continuance commitment.

- H2d: Job design has a significant moderate role on the relationship between neuroticism and organizational commitment.

- H2e: Job design has a significant moderate role on the relationship between personality traits and organizational commitment.

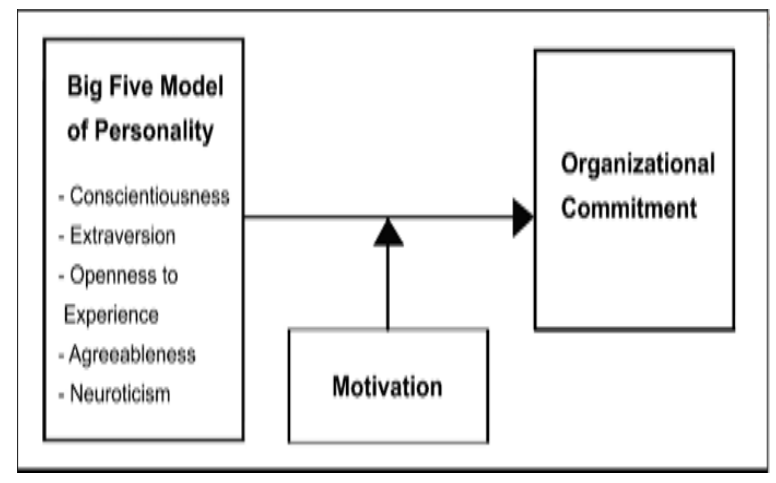

Figure (1): Research Model

\section{Methodology}

\subsection{Participant and Data Collection}

Data has been collected for this study by utilizing a questionnaire used for conducting the opinions of 241 academic and administrative employees in an educational institution in Turkish Republic of Northern Cyprus. The questionnaire has been spread on participants by hand and collected through out a week.

\subsection{Measurements and Research Instruments}

NEO-PI-R, 30 item scale

The beginning of these personality measurements go back to analyzing the sixteen personality factors (16 PF) questionnaire for Cattell el al. (1970). In 1970 Costa and $\mathrm{McC}$ rae tried to find the relationship among the 16 PF traits and then summarized the related traits to clusters to contain three basic facets: Neuroticism, extraversion, and Openness to experience called three factor model (NEO). But later in 1980 Costa and McCrae found that there are no differences in age as claimed in NEO, the results of the above conduction led to forming NEO Inventory questionnaire, NEO Inventory was widely implemented in many aspects 
such as psychology wellbeing, ego development, and vocational interests. NEO Inventory showed a convergence validity with other instruments, but it was criticized by incapability of addressing individual differences utterly. NEO model was improved to contain two additional personality traits conscientiousness, agreeableness and forms a fivefactor model in 1983 which provided a robust description of personality traits in the natural language. Then NEO personality Inventory NEO-PI was constructed. In 1992 the revised NEO personality Inventory NEO-PI-R was published. NEO-PI-R provided scales for all its facets and also included 240 items, but because some people were not understanding few of its items, Costa \& McCrae wrote new items in a simple language or vocabulary to form NEO-PI-3 which characterized by higher readability. All above inventories were considered long scats and need long time to be answered while most of the researchers are usually suffering from serious limitations of their time, as a result NEO Five- Factor Inventory NEO-FFI was formed to include just 12-item scales for measuring each facet (Boyle, G.J, Barton, K. (n.d.)). The coefficient alpha for NEO-PI-R items are analyzed in Costa \& McCrae (1992) as the following: openness $(\alpha=0.77)$, extraversion $(\alpha=0.75)$, conscientiousness $(\alpha=0.71)$, agreeableness $(\alpha=0.74)$, and Neuroticism $(\alpha=0.79)$.

This study adopted NEO-PI-R, this inventory considered the most appropriate instrument for measuring personality traits of our research population which includes employees in educational institution.

The personality section of our questionnaire will measure six facets in each of the five personality traits. The five personality traits conducted in this study are: Openness: Under this topic, the questionnaire tries to assess employees to understand if they are eager to learn (curious), original, creative, open- minded, and simple.
Conscientiousness: In this study NEO-PI-R tries to identify which individual is conscientious through six statements assessing how the person accomplishes his work, intelligent decisions, thinking on consequences before taking an action, discipline.

- Extraversion: In this item of NEO-PI-R questionnaire, researchers try to identify individuals who are talkative, sociable, energetic, participating in social activities, and rounded by many people.

Agreeableness: Agreeableness people are nice, kind, helpful, trusting, generosity, and sympathetic.

- Neuroticism: This item assesses individuals who are anxious, panic, stress, worry, moody, and unhappy people.

Organizational Commitment Questionnaire OCQ, 24item scale

The OCQ for this study is adopted from (Allen \& Meyer, 1990) without making any change. Organizational commitment questionnaire has assessed employees' attachment to their organizations through three dimensions; affective, normative and continuance commitment. Each item category includes eight questions assessing many aspects clarifying how employees are committed to their organization. The coefficient alpha for OCQ items are as following:

Affective commitment scale (SCS) ( $\alpha=0.87)$, Continuance Commitment Scale (CCS) $(\alpha=0.75)$, and Normative Commitment Scale (NCS) $(\alpha=0.79)$.

Work Design Questionnaire WDQ

In 2006, Morgeson and Humphrey proposed a developed and comprehensive measure of work design which is WDQ after revising and analyzing all the available measures of job design that characterized by weak comprehensiveness and poor quality psychometric.

WDQ includes four occupational categories comprising 21 characteristics of work motivating 
individuals through different aspects such as task characteristics, knowledge characteristic, social characteristics, and work context. However, for this study we adopt WDQ with some changes. We tried to study the effects of motivation on individuals through job design. So accordingly, and based on a model proposed by Hackman and Oldham called "Job Characteristics Model", we will choose Task significance, Task identity, Autonomy, and feedback from job and Task characteristics category, while skill variety will be chosen from knowledge characteristics, in an attempt to analyze job design factors as an aspect of motivation for educational institution employees (Morgson \& Humphrey, 2006).

Internal consistency or coefficient alpha for WDQ items in this study were as follows:

Skill variety $(\alpha=.86)$, Task identity $(\alpha=.88)$, Task significance $(\alpha=.87)$, work- schedule autonomy $(\alpha=$ .85), decision- making autonomy ( $a=.85)$, work methods autonomy $(a=.88)$, and Feedback from job ( $\alpha$ $=.86)$.

All responses to our questionnaire NEO-PI-R, OCQ, and WDQ were scored on a 5-point Likert scale, options for respond ranged from 1 (strongly disagree) to 5 (strongly agree).

\section{Results and Discussions}

In this study, different statistical methods in SPSS program such as Pearson Correlation, Linear Regression, and Partial Correlation are used to analyze the data collected from 241 academic and administrative employees in order to determine the relationship between the study's different variables.

Table 1: Descriptive statistics

\begin{tabular}{lcc}
\hline \hline Variables & $\mathbf{M}$ & $\mathrm{SD}$ \\
\hline 1-Extraversion & 3.74 & .91 \\
\hline 2-Agreeableness & 3.72 & .79 \\
\hline 3-Conscientiousness & 3.68 & .91 \\
\hline 4-Neuroticisim & 3.05 & 1.20 \\
\hline 5-Openness & 3.68 & .72 \\
\hline 6-Affective Commitment (AC) & 2.60 & .97 \\
\hline 7-Continuance Commitment (CC) & 2.84 & 1.09 \\
\hline
\end{tabular}

8-Normative Commitment (NC) $\quad 2.39 \quad .84$

Table 2: correlations of variables

\begin{tabular}{|c|c|c|c|c|c|c|c|}
\hline Variables & 2 & 3 & 4 & 5 & 6 & 7 & 8 \\
\hline 1-Extraversion & - & & & & & & \\
\hline 2-Agreableness & $.350^{* 4}$ & & & & & & \\
\hline 3.Conscientiousness & $.225^{* *} \quad 264^{* *}$ & & & & & & \\
\hline 4-Neuroticisim & $.271^{* *} .42^{* *}$ & $.151^{*}$ & & & & & \\
\hline 5.Openness & $.074 \quad .397^{* *}$ & $344^{* *}$ & $.347^{* 4}$ & & & & \\
\hline 6-Affective Commitment (AC) & $-615^{* *}-279^{* *}$ & .110 & $.705^{* 4}$ & $-295^{* *}$ & & & \\
\hline 7-Continuance Commitment (CC) & $-.650^{4 *}-422^{4 *}$ & $.276^{* *}$ & $.665^{3 *}$ & $.190^{* *}$ & $.808^{4 *}$ & & \\
\hline 8-Normative Commitment (NC) & $-4388^{* 4}, 022$ & $-437^{* *}$ & $.512^{* *}$ & $-364^{* *}$ & $.637^{* *}$ & $.577^{*}$ & \\
\hline
\end{tabular}

Table 2 shows a strong negative relationship between personality traits and organizational commitment $(r=-$ .729 , sig $=.000)$ which means that the independent variable (personality traits) and dependent variable (organizational commitment) move in the opposite direction as shown in graph (1). The results of correlation statistics shown a general negative relationship of all five factors of personality with all the dimensions of organizational commitment, while empirical findings of past studies in personality and organizational commitment generalized a wide range of divers directions of relationships and mostly a positive relationship of conscientiousness with affective commitment (AC) and a general negative relations of neuroticism with affective commitment (AC) (Matzler and Renzl, 2007; Naquin and Holton, 2002; Farrukh, Ying, and Mansori, 2017). The reason behind this study's unique results might goes back to the atmosphere and work environment of study's participants in which the studied university was suffering from massive financial crisis that expected to be affected on the organizational behavior and thoughts of its employees as they were paid half of their salaries for more than seven months earlier, as well as, these results might be caused by the existence of a mix between expatriate and indigenous individuals, this situation might affect their behavior toward a negative aspect specially if they witness a diverse treatment to the favor of indigenous employees. 


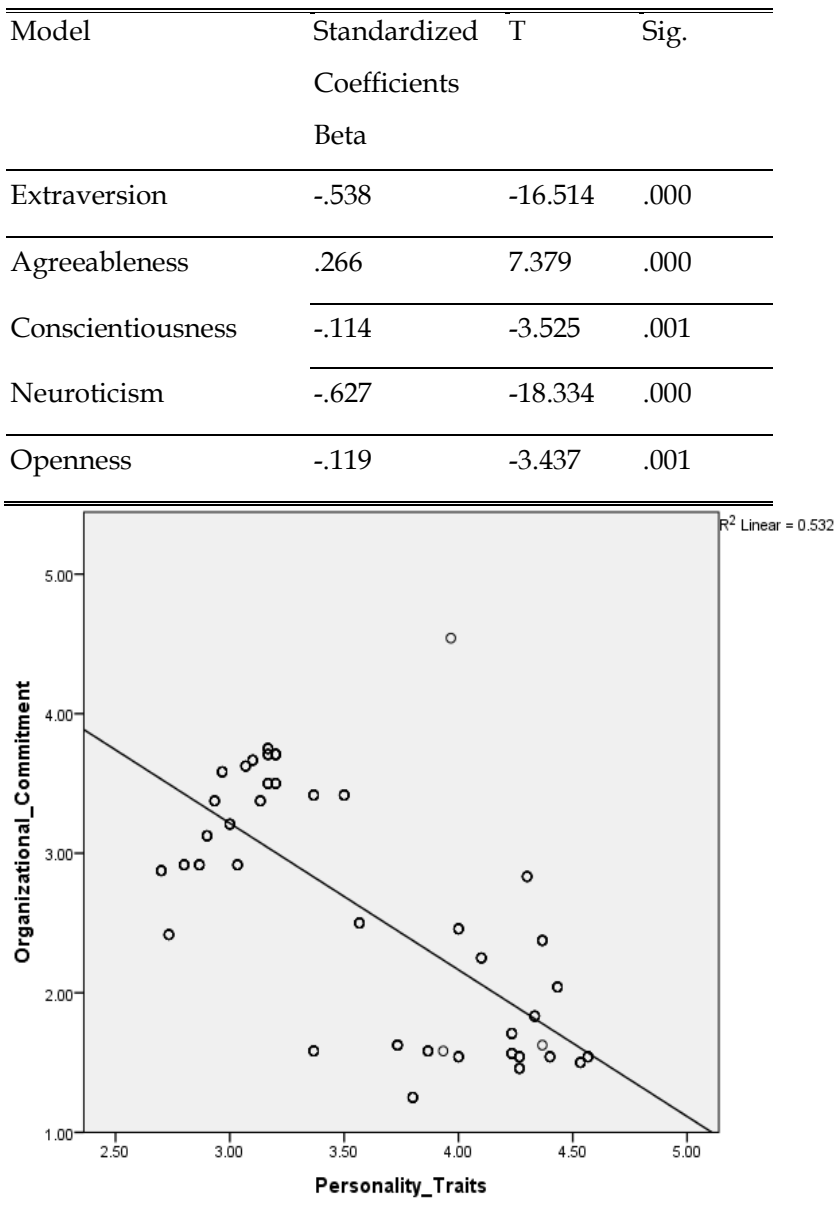

Graph 1: correlation between personality traits and organizational commitment

In order to determine the effect of each personality trait on the commitment of employees, linear regression are used, $\mathrm{R}$ Square for this relationship is .794 which means that $79 \%$ of the negative changes or effects are causing by personality traits and must be taken as a serious indicator in different institutions for the scope of effect that personnel's behavior, attitudes, and thoughts have on organizations processes specially in developing countries that witness a weak understanding of rules and legislations, fragile controlling functions, unclear jobs designs, and an ignorance of organizations systems and processes. On the other hand, $21 \%$ of changes to organizational commitment caused by other factors.

Table 3: Model Summary and ANOVA

\begin{tabular}{cccccc}
\hline \hline Model & R & R Square & Std. Error of the & Estimate & \\
& & & & \\
\hline 1 & $.891^{\mathrm{a}}$ & .794 & .39406 & 181.589 & $.000^{\mathrm{b}}$ \\
\hline \hline
\end{tabular}

Table 4: T Test Results

Table 4 shows the slop of every personality trait and indicate that each personality trait has a different effect on the commitment of employees, extraversion has the greatest negative impact on organizational commitment. (H1 is accepted).

Partial correlation has been used in this study to determine if motivation through job design has a role in modifying the strong negative relationship between personality traits and the different dimensions of organizational commitment.

Table 5: The Interactive Effect Results

\begin{tabular}{|c|c|c|c|c|}
\hline \multicolumn{2}{|c|}{ Hypothesized relationships } & \multirow{2}{*}{$\begin{array}{l}\text { Correlation } \\
-.247\end{array}$} & \multirow{2}{*}{$\begin{array}{l}\text { Sig. } \\
.000\end{array}$} & \multirow{2}{*}{$\begin{array}{l}\text { Results } \\
\text { Accepted }\end{array}$} \\
\hline H2a. EXTR._X_JD & CC. $\rightarrow$ & & & \\
\hline H2b. CONS._X_JD & NC. $\longrightarrow$ & -.184 & .004 & Accepted \\
\hline H2c. AGRE._X_JD & CC. $\rightarrow$ & -.366 & .000 & Accepted \\
\hline H2d.NEUR._X_JD & OC. $\rightarrow$ & -.402 & .000 & Accepted \\
\hline H2e. PT._X_JD & OC. $\longrightarrow$ & -.236 & .000 & Accepted \\
\hline
\end{tabular}

Table 5 shows that motivation could decrease the negative relationship between extraversion and continuance commitment from (-.650) to (-.247) and the negative relationship between conscientiousness and normative commitment has changed from (-.437) to (.184) after adding the motivation as a moderate factor to this relationship, as well as, motivation could decrease the negative relationship between agreeableness and continuance commitment from (.424) to (-.366). The effects of neurotic individuals on organizational commitment decrease if jobs with proper designs provided for them, the results of table 4 supports this insight as the relationship between neuroticism and organizational commitment decreased from (-.714) to (-.402). Table 5 also shows the general role of motivation through job design on the relationship between personality traits and organizational commitment in which this relationship changed from (-.729) to (-.263).

The results of this study support the idea that extrinsic 
motivation has a considerable impact on personnel behaviors and norms toward better organizational commitment. In addition, it supports the approach claiming that extrinsic motivation can displace the value of the intrinsic motivation which usually represents the behavior and norms of individuals.

\section{Conclusion}

Achieving organizations' goals and objectives is a complicated process that needs fulfilling the requirements of individual- Job and individualorganization fit, to do that, the organization, first, has to follow proper ways to select their personnel through applying scientific tests that best help it to understand the personality of each participant and then deciding if his/ her personality traits fit the organization or not, in which it seems not to be enough to hire academically qualified individuals in specific institutions without testing them to ensure their validity to be job or person- organization fit, that might result in their unwillingness to participate in achieving organizations goals. Second, cognitive abilities or hard skills are considered very important asset for nowadays organization in which it could help performing the job better than rivals and achieving competitive advantages. Third, motivation through preparing good job design and work environment considered an important incentive leading employee to achieve organization's goals that all enhance employee satisfaction.

Individual psychology has a critical influence on their attitudes and the degree of their attachment to the organization (organizational commitment). These individual differences are the main reasons behind pursuing excellence by some employees, while others are just counting the work hours and merely founded serious in their jobs, so in this case motivation tactics may have a power to full fill employees needs and encourage them to achieve organization goals.

Individual differences affect positively or negatively on the workplace, because individuals usually bring their behavior (personality traits), attitudes, and abilities to the workplace. Based on interactionist approach, individuals interact with surrounding circumstances and show different attitudes accordingly. Work place environment is crucial factor enhancing or frustrating employees' participation and environment. We can say that the design of the job is consider one of the most important motivators that most employees around the world are caring about and affect their organizational commitment beyond the much of financial and other benefits they get it.

Nowadays, organizations become more social and affected by the psychological behaviors of employees and managerial staff equally, in which employees can impact on organization's performance. Vice Versa, organizations personality affects its employees through their processes and rules, in which weak control function in institutions lead to the settlement of many informal groups that sometimes have a negative impact on the behavior and attitudes of other individuals in the organization toward less attachment to organization's objectives.

\section{For Future Studies}

Personality seems to have a great potential role as a predictor of work or organizational behavior. This is what pushing many organizations worldwide to assess the personality of their candidates or new applicants through using different personality tests in an attempt to enhance individuals' attachment to their organization and decrease turnover.

The word commitment has made a considerable confusion and misunderstanding in the literature when authors and researchers tried to distinguish between the different dimensions of commitment which refers to a behavioral and psychological state or level of individuals' attachments to their organizations.

The most logical conclusion could be drawn from this study is that relatively all the personality traits related 
negatively with organizational commitment, and motivation has a significant rule on the relationship between extraversion and continuance commitment and on the general relationship between personality and organizational commitment which means that every trait of personality has a recognized effect on a specific dimension of commitment; therefore, employees' personality has an impact on their attitudes, organizational behavior, and their commitment, and motivation.

In future studies and researches, it is possible to possess the effect of other motivation factors such as awards on the relationship between personality and each dimension of commitment.

\section{References}

1. Altindls, S. (2011). Job Motivation and Organizational Commitment Among the Health Professionals: A Questionnaire Survey. African Journal of Business Management, 5(21), 8601- 8609

2. Ampofo, E. T. (2020). Mediation effects of job satisfaction and work engagement on the relationship between organisational embeddedness and affective commitment among frontline employees of star-rated hotels in Accra. Journal of Hospitality and Tourism Management, 44, 253 -262.

3. Bauer, t. \& Erdogan, b. (2012). An introduction to organizational behavior, [e- book], p.p. 115-116.

4. Baxter, D. \& Pelletier, L. G. (2020). The Roles of Motivation and Goals on Sustainable Behaviour in a resource Dilemma: A self- Determination Theory Perspective. Journal of Environmental Psychology, 69.

5. Beer, A, \& Brooks, C. (2011). Information Quality in Personality Judgment: The Value of Personal Disclosure. Journal of Research in Personality, 42(2), 175185.

6. Boyle, G. J., Malthews, G., \& Saklofske, R. H. (2008). The SAGE handbook of personality theory and assessment. London. Vol 9.

7. Brown, R. B. (1997). Organizational Commitment: Clarifying the Concept and Simplifying the Existing Construct Typology. Journal of Vocational Behavior, 49(3), 230- 251.

8. Caldwell, D. F. \& Burger, J. M. (1998). Personality Characteristics of Job Applicants and Success in Screening Interviews, Personnel Psychology, 51, 119-136.

9. Choong, Y.O., Wong, K.L. \& Lau, T. C. (2011), Intrinsic Motivation and Organizational Commitment in the Malaysian Private Higher Education Institutions: an Empirical Study. International Refereed Research Journal, 11(4), 91-100.

10. Davidson, P., Bucher, B. (1978). Intrinsic Interest and
Extrinsic Reward: The Effects of a Continuing Token Program on Continuing non Constrained Preference, Behavior Therapy, 9(2), 222-234.

11. De Jong, J. P. J., Parker, S. K., Wennekers, S., \& Wu, C.H. (2013). Entrepreneurial Behavior in Organizations: Does Job Design Matter? Entrepreneurship Theory and Practice, 39(4), 981-995.

12. Farrukh, M., Ying, C. W., and Mansori, S., (2017), Organizational Commitment: An Empirical Analysis of Personality Traits, Journal of Work- Applied Management, 9(1), 18-34.

13. Fowler, H. D., Kelly, A. O., Johnson, J., \& Waite, M. (2019). Sustainability and ideology-infused psychological contracts: An organizational- and employee-level perspective. Human Resource Management Review, 30(3).

14. Ghosh, S., Swamy, (2014). A Literature Review on Organizational Commitment- A Comprehensive Summery. Journal of Engineering Research and Application, 4(12), 04-14.

15. Hackman, J. R., \& Oldham, G. R. (1975). Development of the Job Diagnostic Survey. Journal of Applied Psychology, 60(2), 159-170.

16. Judge, T. A., Higgins, C. A., Thoresen, C. J., \& Barrick, M. R. (1999). The Big Five Personality Traits, General Mental, and Career Success Across the Life Span, Personnel Psychology, 52(3), P. 621.

17. Kaplan, H. R., Tausky, C., \& Bolaria, B. S. (1972). The human relations view of motivation. Organizational Dynamics, 1(2), 67-80.

18. Kim, M. J., Bonn, M., Lee, C.-K., \& Kim, J. S. (2019). Effects of employees' personality and attachment on job flow experience relevant to organizational commitment and consumer-oriented behavior. Journal of Hospitality and Tourism Management, 41, 156-170.

19. Kohn, m. 1., \& schooler, c. (1983). Work and personality: an inquiry in to the impact of social stratification. Norwood, NJ: Ablex.

20. Kuvaas, B., Buch, R., Weibel, A., Dysvik, A., \& Nerstad, C. G. L. (2017). Do intrinsic and extrinsic motivation relate differently to employee outcomes? Journal of Economic Psychology, 61, 244-258.

21. Matzler, K. \& Renzl, B. (2007), Personality Traits, Employee Satisfaction and Effective Commitment, Total Quality Management, 18(5), 589-598.

22. Mawhinney, T. C., Dickinson, A. M., \& Taylor, L. A. (1989). The Use of Concurrent Schedules to Evaluate the Effects of Extrinsic Rewards on "Intrinsic Motivation", Journal of Organizational Behavior Management, 10(1), 109129.

23. Min, H. \& Su, S. (2020), Examining Relationships between Personality Profile and Organizational Health Outcomes, Personality and Individual Differences. 164, 1-9.

24. Morgeson, F. P. \& Humphrey, S.E. The work Design Questionnaire (WDQ): Developing and validating a comprehensive measure for assessing Job Design and the Nature of Work, Journal of applied psychology, 91(6) 132-1339. 
25. Naquin, S.S. and Holton, F. (2002), The Effects of Personality, Affectivity, and Work Commitment on Motivation to Improve Work Through Learning, Human Recourse Development Quarterly, 13(4), 357-376.

26. Rubenstein, A. L., Zhang, Y., Ma, Q., Morrison, H., \& Jorgensen, D. F. (2019). Trait expression through perceived job characteristics: A meta-analytic path model linking personality and job attitudes. Journal of Vocational Behavior, 112, 141- 157.

27. Shah, S. \& Ayub, M. (2021). The Impact of Person-Job Fit, Person-Organization Fit on Job Satisfaction. Journal of Entrepreneurship, Management, and Innovation, 3(1), 57 76.

28. Siachou, E., Trichina, E., Papasolomou, I. \& Sokka, G. (2021), Why Do Employees Hide their Knowledge and what are the Consequences? A Systematic Literature Review, Journal of Business Research. 135, 195-213.

29. Taylor, F. W. (1911). Principles of Scientific Management. American Magazine, 71, 570-581

30. Woods, S. A., West, M. A. (2010). The Psychology of Work and Organizations, United Kingdom, British Library Cataloguing, P. 6. 